\title{
ЗАКОНОМЕРНОСТИ СОЧЕТАЕМОСТИ СРЕДСТВ СВЯЗИ В ПОЛИПРЕДИКАТИВНЫХ СЛОЖНЫХ ПРЕДЛОЖЕНИЯХ В РУССКОМ И УКРАИНСКОМ ЯЗЫКАХ
}

\begin{abstract}
Т.П. СТАКАНКОВА. ЗАКОНОМІРНОСТІ СПОЛУЧУВАНОСТІ ЗАСОБІВ ЗВ'ЯЗКУ В ПОЛІПРЕДИКАТИВНИХ СКЛАДНИХ РЕЧЕННЯХ У РОСІЙСЬКІЙ ТА УКРАЇНСЬКІЙ МОВАХ.

У російській та украӥнській мовах широковживані поліпредикативні складні речення (ПСР). У формі ПСР передається структура розчленування дійсності на більш високому рівні, ніж у простому й елементарному складному реченні, що дозволяс повніше охопити ситуацію $i$ тим самим пізнати ії. Ці речення мають свої специфічні ознаки. До ции ознак відносяться засоби зв'язку, а серед них у першу чергу - сполучники і сполучні слова, які беруть безпосередню участь у вираженні відношень між частинами і конституюють форму складного речення. Порівняльний аналіз російських і украӥнських ПСР свідчить про наявність в них контактних засобів зв'язку. У статті розглядаються закономірності сполучуваності засобів зв'язку в споріднених мовах. Проведений аналіз дозволяе стверджувати, що можливості сполучуваності засобів зв'язку в них неоднакові: одні сполучуються вільно, інші зовсім не сполучуються. Обом мовам властиві однакові закономірності. А це свідчить про те, щзо в російській і украӥнській мовах існують не тільки однакові форми відображення дійсності, але й однакові закономірності будови складних висловлювань, у яких відображається те або те явище дійсності.
\end{abstract}

Ключові слова: поліпредикативне складне речення, контактні засоби зв'язку, споріднені мови, сполучники, сполучні слова, сполучуваність.

Т.П. СТАКАНКОВА ЗАКОНОМЕРНОСТИ СОЧЕТАЕМОСТИ СРЕДСТВ СВЯЗИ В ПОЛИПРЕДИКАТИВНЫХ СЛОЖНЬХ ПРЕДЛОЖЕНИЯХ В РУССКОМ И УКРАИНСКОМ ЯЗЫКАХ.

В русском и украинском языках широко употребляются полипредикативные сложные предложения (ПСР). В форме предикативного сложного предложения передается структура расчленения действительности на более высоком уровне, чем в простом и элементарном сложном предложении, что позволяет полнее охватить ситуацию и тем самым познать ее. Эти предложения имеют свои специфические признаки. К этим признакам относятся средства связи, а среди них, прежде всего, скрепы - союзы и союзные слова, которые принимают непосредственное участие в выражении отномений между частями и конституируют форму сложного предложения. Сопоставительный анализ русских и украинских полипредикативных сложных предложений свидетельствует о наличии в них контактных средств связи. В статье рассматриваются закономерности сочетаемости средств связи в родственных языках. Проведенный анализ ПСР позволяет утверждать, что возможности сочетаемости средств связи в них неодинаковые: одни сочетаются свободно, другие совсем не сочетаются. Обоим языкам свойственны одинаковые закономерности. А это свидетельствует о том, что в русском и украинском языках существуют не только одинаковые формы отражения действительности, но и одинаковые особенности построения сложных высказываний, в которых отражается то или иное явление действительности.

Ключевые слова: полипредикативные сложные предложения, средства связи, контактные средства связи, сочетаемость, союзы, союзные слова.

T.P. STAKANKOVA. THE PATTERNS OF COMPATIBILITY OF THE MEANS OF CONNECTION IN THE POLYPREDICATIVE COMPLEX SENTENCES IN THE RUSSIAN AND UKRAINIAN LANGUAGES.

Polypredicative complex sentences are common in the Russian and Ukrainian languages. The structure of the unbundling of the reality is conveyed on a higher level by the polypredicative forms comparing to the simple complex sentence, which helps to cover the situation more fully. The sentences of the named type have their specific features. They include means of connection, i.e. conjunctions and connectives, which take part in the expression of the relationships between the parts and

(C) Т.П. Стаканкова, 2019

https://doi.org/10.34142/2312-1572.2019.02.68.03 
create the form of a complex sentence. The comparative analyses of the polypredicative complex sentencesin the Russian and Ukrainian languages shows that there are contact means of connection. The article studies the patterns of the compatibility of the means of connection in the languages of the related group. The analysis of the polypredicative complex sentences proves that the possibilities of compatibility of the means of connection are not equal: some of them can be easily combined, others cannot be combined. Similar patterns exist in both languages. It, in turn, proves that there are not only similar form of the representation of the reality, but also similar patterns of the structure of the complex sentences, which depict different aspects of the reality.

Key words: polypredicative complex sentence, means of connection, contact means of connection, compatibility, conjunctions, connectives.

В русском и украинском языках полипредикативные сложные предложения (далее ПСП) широко употребляются в различных сферах языкового общения. Им посвящена многочисленная литература. Это исследования И.А. Василенко, Г.В. Валимовой, Г.Ф. Калашниковой, Г.Ф. Гавриловой, З.Н. Литвиной, Г.П. Уханова, В.А. Шитова и др. В украинском языке ПСП посвящены исследования А.Е. Вербицкого, Б.М. Кулика, И.К. Кучеренко Г.Н. Горяной, К.Ф. Шульжука, М.В. Симулика и др. В форме ПСП передается структура расчленения действительности на более высоком уровне, чем в простом и элементарном сложном предложении, что позволяет полнее охватить ситуацию и тем самым познать ее. Денотатом ПСП является совокупность нескольких элементарных ситуаций и отношения между ними. Языковой способ представления действительности, выражающийся в типовом значении ПСП, тесно связан со структурой мысли, которая формирует типовое значение. Наличие в языке ПСП является одним из показателей высокого развития мышления и языка.

Создание общей теории синтаксиса полипредикативных сложных предложений выдвигает задачу углубленного изучения и системного описания типов подобных конструкций. А между тем целый ряд вопросов, касающихся ПСП, изучен все еще недостаточно.

ПСП имеют свои специфические признаки. К этим признакам относят средства связи, а среди них в первую очередь скрепы - союзы и союзные слова, которые принимают непосредственное участие в выражении отношений между частями и конституируют форму сложного предложения. Сопоставительный анализ ПСП в русском и украинском языках свидетельствует о наличии в них контактных средств связи: Знаете, он говорит, что когда мы вырастем, то он возьмет нас к себе жить (А.П. Чехов); Я чув, щчо коли кіт перейде дорогу, то чекай якоїсь напасті (А. Дімаров). В обоих языках выделяются следующие разновидности сочетаний средств связи: 1) сочетание двух союзов; 2) сочетание союзного слова с последующим союзом; 3) сочетание союза с последующим союзным словом; 4) сочетание двух союзных слов. В связи с этим особого внимания заслуживает вопрос закономерностей сочетаемости средств связи, возникающих в результате объединения компонентов ПСП в многомерную структуру, и сопоставление их в близкородственных языках.

Анализ ПСП показал, что возможности сочетаемости средств связи в них неодинаковы: одни сочетаются свободно, другие совсем не сочетаются, кроме того, разные комбинации сочетаний средств связи обладают разной употребительностью. Обоим языкам свойственны одни и те же закономерности. А это свидетельствует о том, что в русском и украинском языках существуют не только одинаковые формы отражения действительности, но и одинаковые закономерности построения сложных высказываний, в которых отражается то или иное явление действительности.

Сопоставительный анализ ПСП в русском и украинском языках позволяет выявить ограничения сочетаемости отдельных скреп и сформулировать некоторые закономерности их сочетаемости:

1. Сочетаемые предикативные единицы в предложениях с контактными средствами связи должны быть логически совместимы, поскольку действию логических законов подчиняются все наши мысли. При нарушении же законов логики «мысль утрачивает свою определенность, последовательность и доказательность и становится сбивчивой и противоречивой» [4, с. 292]. Так, в анализируемых предложениях не могут сочетаться два условных союза, ибо это привело бы к нарушению одного из логических законов - закона достаточного основания, согласно которому условие не должно существовать при определенном условии [4, с. 121$]$. 
2. Сочетаемые предикативные единицы в анализируемых конструкциях должны выступать элементами одной и той же ситуации или рассуждения, то есть они должны быть совместимы по смыслу. «Чтобы составить сложное высказывание из элементарных, - отмечает Г.П. Мельников, - необходимо точно установить, что они являются элементами одного и того же универсума (универсальное множество), лишь в этом случае они сопоставимы по смыслу и производное, сложное высказывание тоже приобретает смысл. Иначе получается то, что в народе давно высмеивается шуткой: «В огороде бузина, а в Киеве дядька» [6, с. 338].

3. Сочетаемые средства связи не должны иметь одинаковой или близкой формы. Употребление одинаковых средств связи даже в конструкциях с дистантными средствами связи может создать громоздкость конструкции. Еще И.Я. Киприанович, определяя правила построения периодов, указывал на нежелательность стечения одинаковых союзных средств при последовательном подчинении с дистантными скрепами: «При включении придаточных предложений надо избегать однообразия в построении предложений, и поэтому придаточное, подчиненное другому придаточному предложению, не должно иметь одинаковой с ним формы» [5].

В рассказе украинского писателя И. Франко «Панталаха» нам встретилось интересное предложение: Дав тобі бог здоров'я, дав тобі талант у руки, ще, щя очима побачиш, те руками зробиш, а ти пустився на крадіж, замість спокійно на хліб робити та бога хвалити! (I. Франко). Подобная комбинация одинаковых средств связи становится возможной только в силу синонимичности союзного слова щзо, выступающего первой частью сочетаний скреп, союзному слову який. Об этом свидетельствует и сопоставление данного предложения с его переводом на русский язык: Дал тебе бог здоровья, дал талант в руки, да какой - что глазами не увидишь, руками сделаешь, - а ты воровать пустился, вместо того чтобы спокойно на хлеб зарабатывать и бога славить (перевод с украинского И. Дорбы). Первоначально этот рассказ был написан на польском языке, а затем уже в авторском переводе вышел на украинском. Очевидно, здесь сказалось влияние польского языка. Сам И.Франко в предисловии к изданию писал: «Я передав ті епізоди, не мудруючи та не вдаючися в ніяке філософствування про їх значення. Нехай їх фактична основа говорить сама за себе».

4. Первая часть сочетаний средств связи должна быть способна к комплексному обслуживанию, то есть к обслуживанию сразу нескольких предикативных единиц. Так, в анализируемых конструкциях союз или союзное слово, которому принадлежит первая часть сочетаний средств связи, присоединяет к главному не только придаточное первой степени, но и целый комплекс, состоящий из двух предикативных единиц. Анализ языкового материала свидетельствует о том, что в русском и украинском языках выполнять эту функцию могут асемантические союзы, а также моносемантические союзы, выражающие определенные значения и закрепленные за строго определенными синтаксическими отношениями. Широко употребителен в роли первой части сочетаний скреп в русском асемантический союз что (в украинском языке що), а также моносемантические союзы потому что, так как, ибо и др. (в украинском языке тому що, бо), выражающие только причинные отношения; союзы хотя, несмотря на то что (украинские хоч, незважаючи на mе що), выражающие только уступительные отношения; союз так что (в украинском так що), выражающие следственные отношения, и др.: Мне кажется, что если я сделаю еще хоть один шаг среди этой грозной темноты, я тоже полечу в глубокую, холодную и грязную трясину (А. Куприн); Я прикинув на око оранку, розтер у жмені грудку супіску $i$, виказуючи своє розуміння агрономічних секретів, зауважив, що, коли пофортунить на погоду та буде добре поліття, то, дивись, чого доброго, ще й буде колгосп з гречкою (Ю. Збанацький); Потерял он, видимо, его ненадолго, потому что, когда открыл глаза, Макшеев был тут же (А. Иванов); Не вірив, бо коли старші розказували про це, в їхніх очах ти бачив лукавий сміх (Є.Гуцало); Нажитого умения уже недостаточно, хотя, чтобы приобрести его, были отданы все силь души (В. Каверин); Але, як на лихо, Уповайченков нічого не розумів $і$ нікого не помічав навколо себе, хоч, коли б був трохи досвідченіший, він міг би помітити, що тут щось готується (Л. Первомайський). Очевидно, это можно объяснить тем, что асемантические союзы не являются носителями закрепленной за ними смысловой оценки и выполняют в предложении лишь роль общего показателя синтаксической связи. А моносемантические союзы «нейтрализуют воздействие контекста на создание тех или иных смысловых отношений между частями сложного предложения: они сами однозначно выражают эти отношения» $[9$, с. 9]. 
В обоих сопоставляемых языках первой частью сочетаний средств связи не могут выступать полисемантические союзы, способные в разных условиях выражать разные синтаксические отношения. В русском языке это союзы если, коли, раз, в украинском - якщо, коли, якби и др. В отличие от моносемантических союзов, способных выступать первой частью контактных сочетаний, значение полисемантических союзов зависит от характера смысловых отношений между частями сложного предложения. Так, русский полисемантический союз когда и украинский коли могут употребляться при использовании одного и того же временного плана действия, заключенного в компонентах сложного предложения. Главным значением устанавливаемых отношений между компонентами сложного предложения в этом контексте для этих семантических союзов является значение временной обусловленности. Соотношение же разных временных планов уже само по себе создает иное содержание отношений между компонентами сложного предложения. При этом видоизменяется значение союзов.

Русский союз если и украинский якщо имеют условное значение в том случае, когда сочетаются с формами глаголов, имеющими потенциально-возможное или ирреальное значение.

Следовательно, значение полисемантических союзов выявляется в контексте. Видимо, поэтому лексический состав придаточных, оформленных этими союзами, не может находиться после придаточного второй степени. В наших материалах зафиксирован всего один случай, где в роли первой части сочетаний средств связи употребляется союз если: Узнав, что доктор еще не вставал, Левин из разных планов, представлявшимся ему, остановился на следующем: Кузьме ехать с запиской к другому доктору, а самому ехать в аптеку за опиумом, а если, когда он вернется, доктор еще не встанет, то, подкупив лакея или насильно, если тот не согласится, будить доктора во что бы то ни стало (Л. Толстой). Сочетание если когда в приведенном предложении становится возможным только потому, что на фоне временного союза когда союз если сразу конкретизирует свою семантику. Однако такие сочетания средств связи не характерны как для русского языка, так и для украинского, они являются индивидуально-авторскими.

Таким образом, сочетаемость средств связи в ПСП сопровождается определенными ограничениями, которые накладываются на выбор союза-посредника.

5. Второй частью сочетаний средств связи в русском и украинском языках выступают лишь те скрепы, которые оформляют предложения гибкой структуры, то есть те, которые способны вводить препозитивную придаточную часть. В этой функции могут выступать скрепы, оформляющие условные, причинные, временные, целевые и др. предложения. И, наоборот, не могут выступать скрепы, оформляющие относительно-распространительные предложения, придаточные следствия, а также некоторые предложения с малой гибкостью.

Следовательно, сочетаемость средств вязи в ПСП в русском и украинском языках сопровождается определенными ограничениями, которые накладываются на выбор второго союза или союзного слова.

Исследование сочетаемости средств связи в русском и украинском языках свидетельствует о том, что большинство русских ПСП с контактными средствами связи находят свое соответствие в украинском языке, что обусловлено общностью их происхождения. Но вместе с тем частотность их употребления различна. А это позволяет сделать вывод о том, что каждый из сопоставляемых языков развивается в соответствии со своими внутренними законами. Различен и семантический объем русских и украинских скреп, входящих в состав сочетаний, вследствие чего несколько украинских сочетаний могут передаваться одним русским и наоборот.

\section{ЛИТЕРАТУРА}

1. Ардентов Б.П. «Что» в современном русском языке. Кишинев, 1973. 90 с.

2. Арутюнова Н.Д. О синтаксической сочетаемости слов в испанском языке. Филологические науки. 1962. № 2. С. 31-40.

3. Ахманова О.С. Словарь лингвистических терминов. М., 1966. 445 с.

4. Горский Д.Н. Логика. М., 1963. 292 с.

5. Киприанович И.Я. Синтаксис русского языка, сличенный с синтаксисом классических языков. СПБ, 1885. 112 с.

6. Мельников Г.П. Систематология и языковые аспекты кибернетики. М., 1978. 338 с. 
7. Степанов М.Д. О «внешней» и «внутренней» валентности слова. Иностранные языки в школе. 1967. № 3. С. 13-19.

8. Страхова В.С. Валентность в структуре сложноподчиненного предложения: автореф. дисс. ... канд. филол. наук. М., 1972. 23 с.

9. Федоров А.К. Система подчинительных союзов в современном русском языке: автореф. дисс. ... д-ра филол. наук. М., 1972. 39 с.

10. Шмелев Д.Н. О значении синтаксических единиц // Инвариантные синтаксические значения и структура предложения. М., 1961. С. 156-162.

(Статья поступила в редаки̧ию 14 марта 2019 г.) 